\title{
Recent trends of thunderstorm and hailstorm frequency and their relation to atmospheric characteristics in southwest Germany
}

\author{
M. Kunz, ${ }^{a *}$ J. Sander ${ }^{a}, \mathrm{~b}$ and Ch. Kottmeier ${ }^{\mathrm{a}}$ \\ ${ }^{a}$ Institut für Meteorologie und Klimaforschung, Universität Karlsruhe/Forschungszentrum Karlsruhe, Karlsruhe, Germany \\ ${ }^{\mathrm{b}}$ Deutsches Zentrum für Luft-und Raumfahrt, Institut für Physik der Atmosphäre, Oberpfaffenhofen, Wessling, Germany
}

\begin{abstract}
In the context of climate change, it is of particular interest whether extreme events connected to severe thunderstorms have been increasing in number or intensity over the past few decades. Due to their small horizontal extent, such events are not entirely and uniquely captured by current observation systems. To obtain comprehensive information about the convective activity in the state of Baden-Württemberg (southwest Germany), we analysed different datasets for the period 1974-2003. They comprise thunderstorm days detected at synoptic stations, hail damage data from a building insurance company, large-scale circulation and weather patterns, and convective indices derived from radiosonde observations at 12:00 UTC.

While the annual number of thunderstorm days remained almost unchanged in the mean, hail damage and hail days significantly increased in the last three decades. Both damage and additional radar data indicate that the majority of hail days can be attributed to three specific circulation patterns. Two of the three patterns associated with the preferable occurrence of hail show a significant increase.

Most of the commonly used convective indices that depend upon surface temperature and moisture reveal a positive trend regarding both the annual extreme values and the number of days above/below specific thresholds. A relationship was established between the indices and the annual number of hail damage days, yielding correlation coefficients between 0.65 and 0.80 . In contrast to this, indices derived from temperature and moisture at higher levels exhibit either a negative or no significant trend. It is shown that the trend directions of the indices may be attributed to differential temperature and moisture stratification in the various atmospheric layers. The significant positive trends of both surface temperature and water vapour can be concisely expressed by an increase in wet-bulb potential temperature. This indicates the presence of warmer parcels throughout the whole troposphere during convection. Copyright (C) 2009 Royal Meteorological Society
\end{abstract}

KEY WORDS climate change; thunderstorm day; hail day; hail climatology; hail damage; insurance; convective indices

Received 10 March 2008; Revised 12 January 2009; Accepted 12 January 2009

\section{Introduction}

Thunderstorms pose a significant threat to modern societies and their assets. Despite their local-scale characteristics, severe thunderstorms and associated extreme events like heavy rainfall, hail, gusts, or tornadoes, cause considerable damage to agriculture, buildings, or infrastructure facilities. In the federal State of Baden-Württemberg (southwest Germany; see Figure 1), 38\% of all damage to buildings (average, 1986-2004) caused by natural hazards can be attributed to deep convective events (Kunz, 2007b). Moreover, almost a quarter of the total damage $(24.3 \%)$ is caused by large hail exclusively, yielding a mean annual loss of $€ 26.9$ million (inflation-adjusted to 2005 with an assumed insurance density of $100 \%$ ). In the past, single severe hailstorms caused up to $€ 100$ million in damages to buildings in this region.

* Correspondence to: M. Kunz, Institute for Meteorology and Climate Research (IMK), University of Karlsruhe (TH), Kaiserstraße 12, D76128 Karlsruhe, Germany. E-mail: michael.kunz@imk.fzk.de
In light of global warming (IPCC, 2007), the question arises as to whether any evidence suggests an increase in severe thunderstorm events either in number or intensity. This question is difficult to answer, because current surface observation systems are too coarse to capture all convective events. Remote sensing techniques, on the other hand, are not yet able to uniquely detect these events. For example, Dotzek (2003) and Bissolli et al. (2007) found that the apparent increase of mainly weak tornadoes between 1950 and 2003 is mainly caused by enhanced detection and reporting efficiencies, primarily due to increased public awareness.

A way to overcome the problem of insufficient observations is an approach that links thunderstorm occurrence to large-scale atmospheric conditions. Changes in the synoptic-scale conditions are assumed to have a direct influence on the intensity or the number of thunderstorms. Although the exact mechanisms that favour thunderstorms are very complex and not yet fully understood, the general requirements for a pre-convective environment 


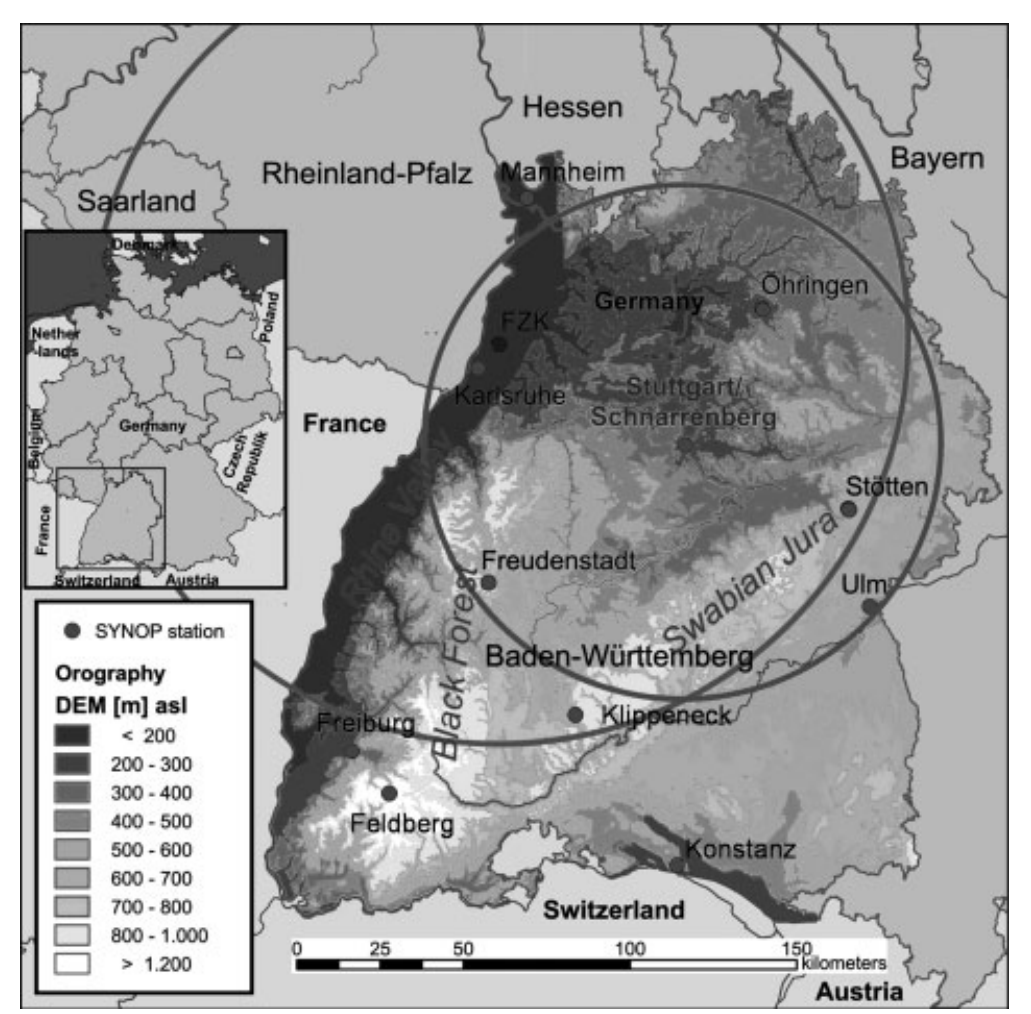

Figure 1. Area under investigation with the radiosonde station of Stuttgart-Schnarrenberg, SYNOP stations, and range of the FZK radar (large circle; the small circle indicates a $70-\mathrm{km}$ radius around the radiosonde).

are well known: atmospheric instability, low-level moisture, and a trigger mechanism (Doswell, 1987; Houze, 1993). These conditions, except for the last one, can be expressed in principle by convective parameters and indices that are assumed to reflect the convective potential of the atmosphere. The indices are calculated from differences in temperature and dew-point temperature at distinct levels, sometimes complemented by dynamic driving forces in terms of wind shear. In many studies, the skill of the various indices derived from either radiosonde observations or model simulations to predict thunderstorms was investigated, for example, by Lee and Passner (1993), Fuelberg and Biggar (1994), Huntrieser et al. (1997), Rasmussen and Blanchard (1998), and Haklander and van Delden (2003). All these studies report a relationship between thunderstorm occurrence and certain threshold values of the various convective indices. A relationship between hail incidence and the convective available potential energy (CAPE) derived from both soundings and NCEP/NCAR reanalysis data, was established by Niall and Walsh (2005) for Australia. Groenemeijer and van Delden (2007) found that instability as measured by the Lifted Index (LI), or CAPE, and 0-6 km wind shear derived from radio soundings independently have considerable skill in distinguishing environments of large hail and of non-hail-producing thunderstorms in the Netherlands. In a recent study, Kunz (2007a) showed that damage-causing hail and local flood events in southwest Germany can be attributed to specific thresholds of several convective indices, in particular the LI and the CAPE.
In addition to atmospheric stability as expressed by the various convective indices, severe convective storms may be attributed to certain weather situations, namely, to those favouring the pre-convective conditions: advection of moist, unstable air masses ahead of large-scale lifting by an upper trough. Several approaches exist for the purpose of classifying the different weather types according to the prevailing pressure fields, the advection of air masses, the cyclonity, and/or the moisture content (Yarnal et al., 2001). By using the objective weather-type classification of the German Weather Service [Deutscher Wetterdienst (DWD)] (Bissolli and Dittmann, 2001), Bissolli et al. (2007) attributed the majority of tornado events to three specific weather types. The present study focuses on the large-scale circulation and weather patterns (CP) according to the classification of Hess and Brezowsky (1977) that consider the location of the prevailing main pressure systems and the horizontal extent of the frontal zone.

The purpose of this paper is to determine whether there is any evidence suggesting an increase in frequency or intensity of thunderstorms, in particular hailstorms, in the last decades. Datasets from different observation systems were analysed and combined: synoptic data (SYNOP) data were used to quantify the number of thunderstorm days. Data relating to losses from a building insurance company were taken in order to estimate the annual variability of loss and hail days. Large-scale weather patterns are related to hail days as detected by the insurance loss data and additional radar reflectivity. Several convective indices derived from radio-sounding 
data are used to investigate possible long-term trends in static stability. The terrain of the investigation area exhibits a certain complexity with the low mountain ranges of the Black Forest and Swabian Jura. It is well known that this region is prone to deep convection (Meißner et al., 2007) and is often associated with damage due to hail, local storms, or floods.

The paper is organized as follows. Section 2 gives an overview of the different datasets used in this study and of the methods applied. Section 3 discusses the annual variability in the number of days with damage-causing hailstorms and thunderstorms. Section 4 examines the longterm variability of specific weather patterns that favour the occurrence of hailstorms and of various convective indices that reflect the pre-convective environment. Discussion and Conclusions follow in the last Section 5.

\section{Datasets and methods}

Since severe thunderstorms occur almost exclusively in the warm season of April to September in Germany, all examinations are restricted to that period. Most of the datasets used refer to a 30-year period between 1974 and 2003. To examine possible trends in the frequency of thunderstorms or related events like hail, information about their occurrence is necessary with a high spatial coverage over a sufficiently long term. Since these requirements have not been met by a single dataset so far, data from different observation systems are used to supplement this study.

Any long-term changes are inferred through a linear regression model. Even if an exponential trend seems to be more appropriate in some cases, only linear trends are derived for consistency and easier comparability. The level of significance is determined by the trend-to-noise ratio $(\mathrm{t} / \mathrm{n})$ that is given by the ratio of the overall trend (slope of the regression line) to the standard deviation, and applying Student's $t$-distribution (Schönwiese, 2000). In addition, the non-parametric Mann-Kendall trend test (MK) is also applied to the data. In most diagrams the confidence intervals that correspond to a $95 \%$ level of significance for the mean of the response variable (von Storch and Zwiers, 2004) and the slope of the regression line are shown.

\subsection{Synoptic station data}

Days with thunderstorm occurrence were identified at eleven different SYNOP stations of DWD for the period between 1949 and 2003. In the SYNOP report, the present and past weather types at and around a station are encoded by a 2-digit code. If any of the numbers 13,17 , 27, 29, 91-99 indicating thunderstorm occurrence due to lightning or audible thunder at or around the station are recorded, the day is classified a thunderstorm day. Because of a change in the observation frequency in 1980, only the three-hourly reports between 06:00 and 21:00 UTC are used in the study.
By comparing station and lightning data, (Haklander and van Delden, 2003) found an average radius of $20 \mathrm{~km}$ around a station, where thunder is audible, while Bissolli et al. (2007) study thunderstorm frequency within a distance of $15 \mathrm{~km}$. As regards the region of BadenWürttemberg, the former radius gives a spatial coverage of approximately one-third of the region, in which thunderstorms may be detected.

\subsection{Insurance loss data and radar data}

Since small-scale severe weather phenomena are usually not captured accurately by any conventional observation system, insurance loss data are used in order to examine the frequency of hail events and their longterm variations. For this study, data of a building insurance company, the Sparkassenversicherung (hereinafter referred to as $\mathrm{SV}$ ), were provided for the period from 1986 to 2003. Building insurance against all kinds of natural hazards was mandatory in Baden-Württemberg until 1994 and offered exclusively by the monopolist Gebäudeversicherung Baden-Württemberg. Hence, the recorded loss data of its successor, SV, are characterized by a high areal coverage and consistency. Separated into five-digit postal code zones, the data comprise the date and the number of notification of claims for each hail damage event. The total number of contracts and insured values per year and postal code zone allow for a data correction to account for the yearly variability of the portfolio, especially for the decrease after the abolition of the insurance obligation in 1994 (100\%) to 2004 (71\%). In the following sections, all analyses will be based on the data adjusted accordingly. A comparison of a sample of hail days derived from insurance data and radar data revealed that some individual claims were assigned to a wrong date, usually one day before or after the actual event. In order to filter out these incorrect events, a lower threshold of 10 claims was applied to define a hail day. A threshold of 50 claims was used to extract the more severe hail days. For the hail damage map, the number of claims was normalized by the number of existing insurance contracts for each postal code zone in order to reduce the effect of population density in the data. This measure is referred to as loss frequency.

When interpreting the results, it must be kept in mind that the loss data are restricted to damage of buildings only and, thus, limited to settlement regions that were affected by large hail. Hailstorms that may have impacts on plants, motor vehicles, or infrastructure facilities are not captured by the SV dataset. Nevertheless, this dataset represents the best documentation available concerning damaging hail occurrence over a broad area for a sufficiently long period of time.

To overcome the constraint of building damage for the identification of hail days, we supplemented the SV data with high-resolution data from the C-band radar of the Institute for Meteorology and Climate Research (IMK), Karlsruhe, between 1996 and 2003. The radar located at the Forschungszentrum Karlsruhe covers a range of 
$120 \mathrm{~km}$ in radius (Figure 1). Radar reflectivity is interpolated on a $1 \times 1 \mathrm{~km}$ grid with a temporal resolution of 10 min (Gysi, 1995). In order to detect events with damage-causing hailstones, a threshold of $65 \mathrm{dBZ}$ was defined for the maximum radar reflectivity in a vertical column. This gives 44 days with severe hail in the 8-year period, that is 5.5 days per year on the average. The hail days identified by radar data agree well with those determined by SV damage reports. Only six days are not captured by the loss data. This discrepancy may be attributed to the different regions covered by the two datasets and the restriction of damage reports to settled regions.

\subsection{Convective indices and large-scale circulation patterns}

From the Stuttgart radiosonde observations (see Figure 1) at 12:00 UTC, various convective indices which allow for the quantification of the thunderstorm potential in the atmosphere between 1974 and 2003 are calculated. These convective indices include Vertical Totals (VT), LI, Showalter Index (SHOW), Deep Convective Index (DCI), different versions of the CAPE, Convective Index (KO), Delta- $\theta_{e}$ Index (DTeI), Potential Instability Index (PII), Total Totals (TT), K-Index, Jefferson Index (Jeff), and Severe Weather Threat Index (SWEAT). Explanations and definitions of the various indices can be found in Table A1 of the Appendix. In the whole period, a total of 5452 complete soundings, that is more than $99.3 \%$ of all possible soundings, were analysed. On days with data loss, the convective indices are interpolated from the preceding and following day according to the synoptic situation (as checked by weather charts and neighbouring radio soundings in Nancy, France). For the estimation of long-term changes in the prevailing atmospheric conditions, different percentiles of the annual frequency distribution (90th, 95th, and 99th percentiles) as well as the number of days per year above/below defined thresholds were calculated.

Finally, the general synoptic conditions on hail days were estimated by means of large-scale CPs according to the classification of Hess and Brezowsky (1977) that was refined later and published by Gerstengarbe and Werner (2005). The 30 possible patterns, including one undefined type, can be grouped into the three main categories of zonal, meridional, and mixed-type circulations. They are determined daily from the mean air pressure distribution at sea level and the 500-hPa geopotential height chart. Furthermore, the location and horizontal extent of the frontal zone are considered. The CPs normally persist for several days, while the entailed weather characteristics remain similar.

\section{Trends of thunderstorm and hail events}

\subsection{Thunderstorm days between 1949 and 2003}

Recall that a day is considered a thunderstorm day if a thunderstorm was detected either by lightning or thunder at any time during the observation hours. Figure 2(a) shows the annual variation of thunderstorm days between 1949 and 2003 for the two stations of Karlsruhe and Stuttgart (locations indicated in Figure 1). The figures give the 5-year moving average and the regression line for the period from 1974 to 2003. In the first period from 1949 until 1980, both sites experienced approximately the same number of thunderstorm days within a year. After this period, however, the curves diverge. Although the maxima and minima frequently coincide on both sites, the annual number of thunderstorm days increases slightly at Stuttgart, while they sharply decrease at Karlsruhe. Different trend directions can also be observed at the other SYNOP stations in Baden-Württemberg (not shown here). Only Freiburg and Stötten, however, exhibit a positive trend that is significant on the $95 \%$ level ( $\mathrm{Si}$ $>95 \%$ )

Considering all 11 SYNOP stations, and determining thunderstorm days according to the present and past weather code independently of the location, large annual variations are obvious but without any trend (Figure 2(b)). During the whole period displayed, the number of thunderstorm days varies between 47 and 81 days. Accordingly, thunderstorms in Baden-Württemberg occur between 25.7 and $44.3 \%$ out of all days in the summer half of the year. This confirms the high probability of thunderstorms in this region.
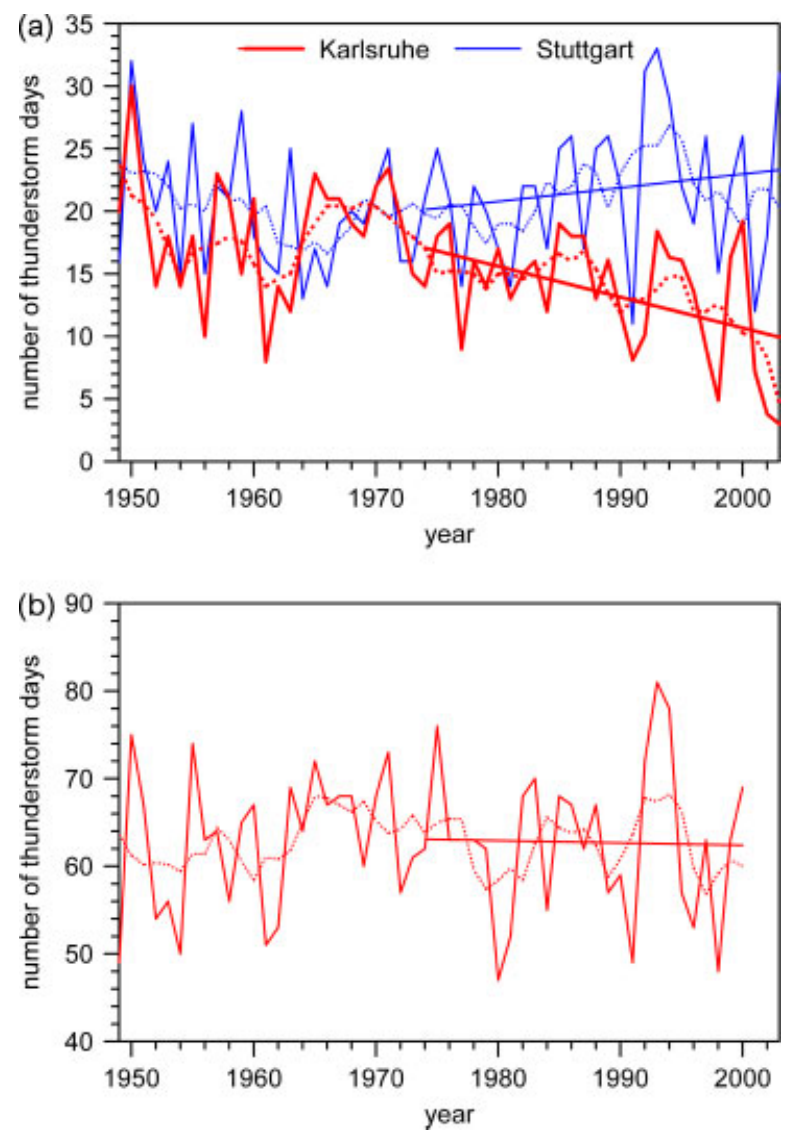

Figure 2. Average number of thunderstorm days at the stations Stuttgart and Karlsruhe (a), and according to the combination of all 11 SYNOP stations in Baden-Württemberg (b). This figure is available in colour online at www.interscience.wiley.com/ijoc 


\subsection{Hailstorms between 1986 and 2004}

To obtain an estimate of the local occurrence of hailstorms and to identify 'hot spots' in the test region, we accumulated the loss frequency for 3-digit postal code zones and integrated over the whole period from 1986 to 2004. The integrated loss frequency may be interpreted as the hazard potential of a specific region. Over the whole area of Baden-Württemberg, significant differences of the loss frequency can be detected (Figure 3 ). The frequency ranges from $f=1.42 \cdot 10^{-3}$ (one damaged building out of a total of 750 per year) to $f=1.37 \cdot 10^{-5}$ (one out of 72992 ). Hot spots with highest damage frequency can be identified north of Karlsruhe, east of the Black Forest Mountains, around Villingen-Schwenningen, near Lake Constance (Singen), and around Ulm (see Figure 1 for locations). Surprisingly, lowest frequencies are found for several postal code zones in the Black Forest. Although it is impossible to deduce a direct relationship between orography and loss frequency from Figure 3, local effects like flow channelling or orographically induced local wind systems causing horizontal convergence zones (Gysi, 1998; Dotzek, 2001) are certainly decisive for the spatial distribution of thunderstorm and hail occurrence.

In light of the fact that hail events occur quite frequently in the area under investigation, high annual losses up to $€ 180$ million arose between 1986 and 2004 . Both the annual amount of loss and the notifications of claims (Figure 4(a)) show a strong temporal increase. In addition, the temporal variability is extremely high. While the number of claims ranges between 512 in 1991 and 59278 in 2002, the related annual loss varies between $€ 1$ million (1988) and $€ 176.9$ million (2002). These two figures show a distinct relationship, indicating an almost constant average loss per claim for the whole period of almost $€ 3000$. Two periods, from 1992 to 1995 and from 2002 to 2004 with highest hail damage can be identified. From 1986 to 1991 and from 1996 to 2001, by contrast, both quantities exhibit their lowest values. The high annual variability, in particular the occurrence of the maxima, is due to the dominance of single extreme events on the total loss, giving a very asymmetric statistical distribution of the loss rates per day. Hence, single severe hailstorms may dominate the total amount of loss in one year. This was the case in 1995 and 2002, where the two costliest events of the whole observation period occurred (22 July 1995 and 24 June 2002). Together, both events caused $30.4 \%$ of the total loss accumulated over the entire 19 years. The high annual variability gives rise to a nonsignificant trend for the annual loss ( $\mathrm{Si}=84 \%$ according to $\mathrm{t} / \mathrm{n})$.

To obtain a result that is less sensitive to single severe storms, we determined all days with hail occurrence for

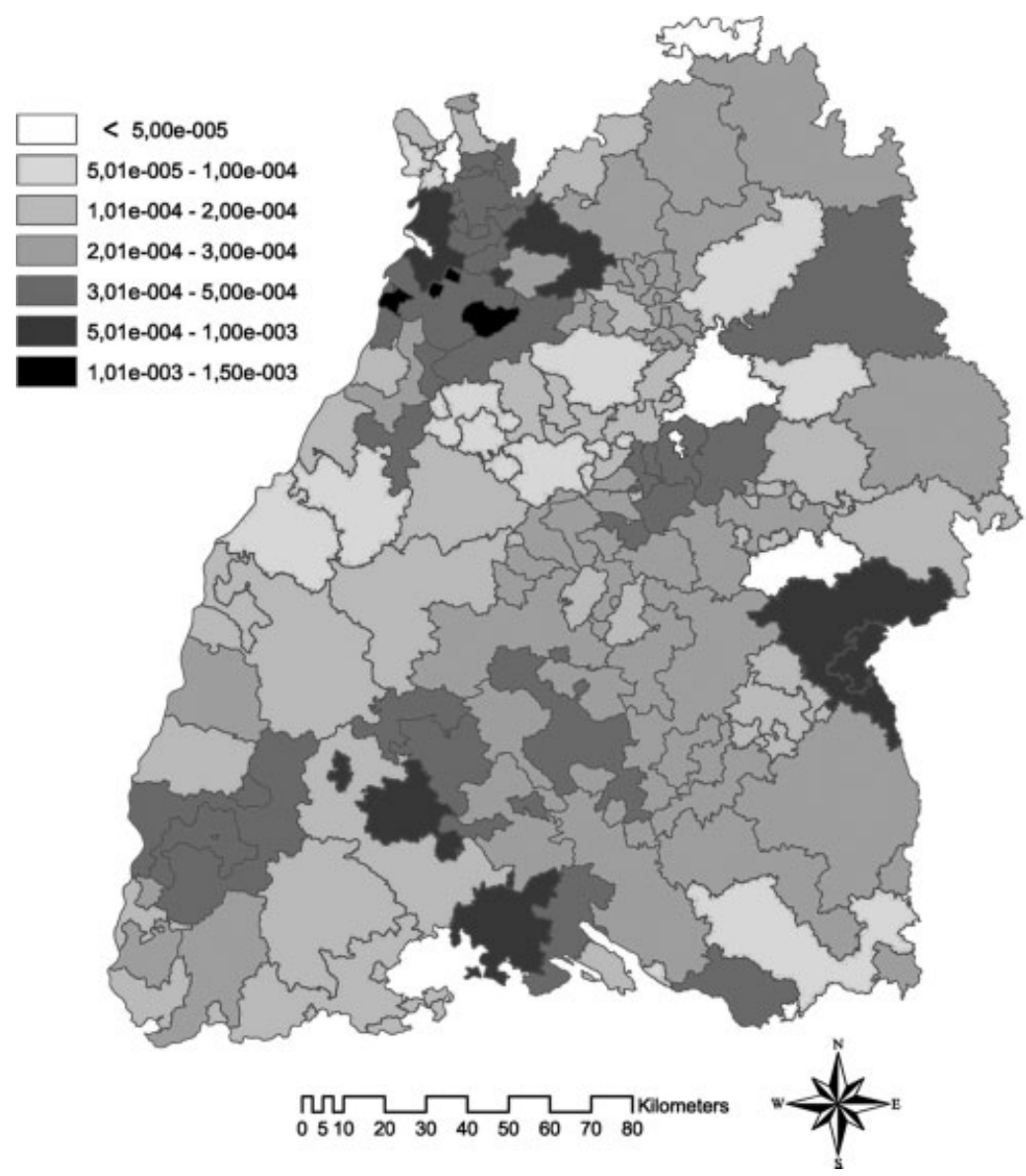

Figure 3. Loss frequency (ratio between notifications of claims and number of contracts) for the three-digit postal code zones over Baden-Württemberg according to the SV loss data between 1986 and 2004. 
the whole observation period irrespective of the location and the amount of loss. A day was classified as a hail day when a lower threshold of 10 or 50 claims (corrected) was reached on a day (Figure 4b). The lower threshold was applied to filter out days that were signed to an incorrect date, while the higher threshold reproduces the more severe events. The two thresholds give an average of 19.4 or 9.2 hail days per year.

In both cases, however, there is a strong increase of hail days with time. The linear trend is significant as
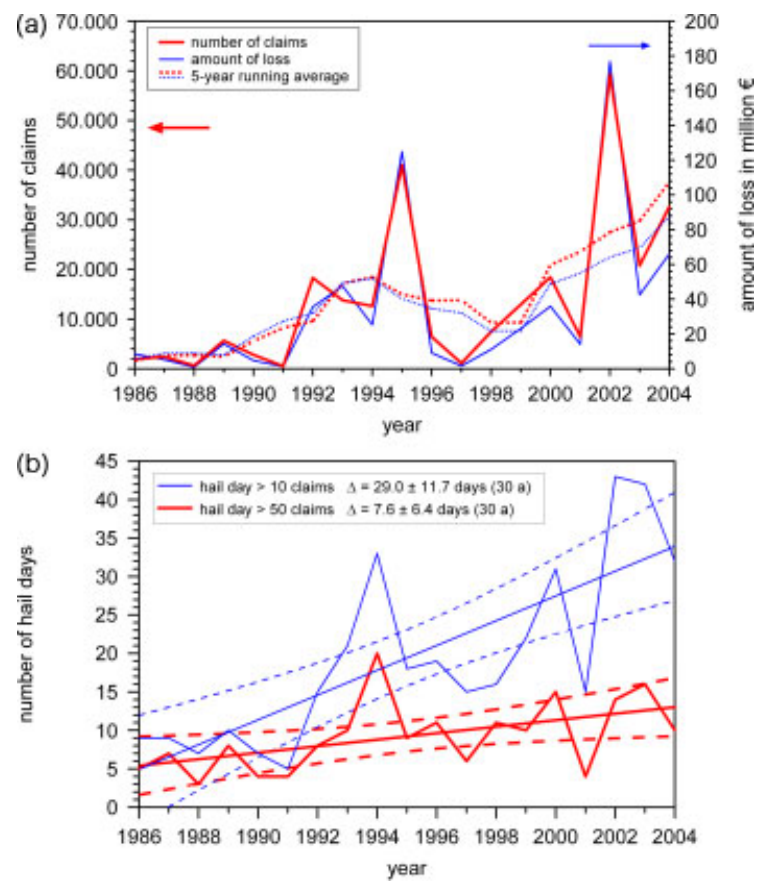

Figure 4. Number of claims and amount of loss per year due to hail damage to buildings (a) and number of hail days per year (b) according to damage reports of the SV building insurance company in Baden-Württemberg. A hail day here means that a threshold of 10 or 50 claims per day is exceeded; indicated are the linear trend (referred to as $\Delta$ ) with $95 \%$ confidence intervals for the whole period, trend curves (solid), and the $95 \%$ confidence intervals for the mean of the response variable (dashed). This figure is available in colour online at www.interscience.wiley.com/ijoc indicated by the $95 \%$ confidence intervals, which does not include any negative or zero slope of the axis. The level of significance for a linear trend according to the $t / n$ and $t$-statistics yields values of 98 and $90 \%$ for the two thresholds of 10 and 50 claims, respectively. A direct relationship to the annual loss (see Figure 4(a)) is not observed, even though some high peaks may coincide. The lack of relationship between hail days and annual loss again confirms the dominance of single severe hail events on the total amount of loss.

\section{Synoptic and ambient conditions during thunderstorm and hail days}

It was shown in the previous section that the frequency of hail days increased in the past decades. Now, atmospheric characteristics shall be examined as a possible reason for the trend. The analyses will be based on large-scale weather patterns and convective indices acting on the regional scale.

\subsection{Circulation and weather patterns}

To investigate whether hail events are related to typical circulation patterns, we determined the prevailing CPs for each hail day as identified by both radar data (44 days) and insurance data ( $>20$ damage reports on a day that give 89 days) between May and August from 1996 until 2003. Although there were some differences in the frequency of the prevailing CPs that favour hailstorms, the distributions of both datasets show good agreement (Figure 5). The CP that is most frequently connected to hailstorms is the ridge of high pressure over Central Europe (BM), where the subtropical high located north or northeast of the Azores is connected to an East European high by a bridge-shaped pressure region over Central Europe (see Figure 6). The frontal zone is typically located northeast of this region, and disturbances may cross Central Europe. As most parts of Central Europe are under anticyclonic influence, convection may develop as 'high-pressure convection' in the warm and moist air

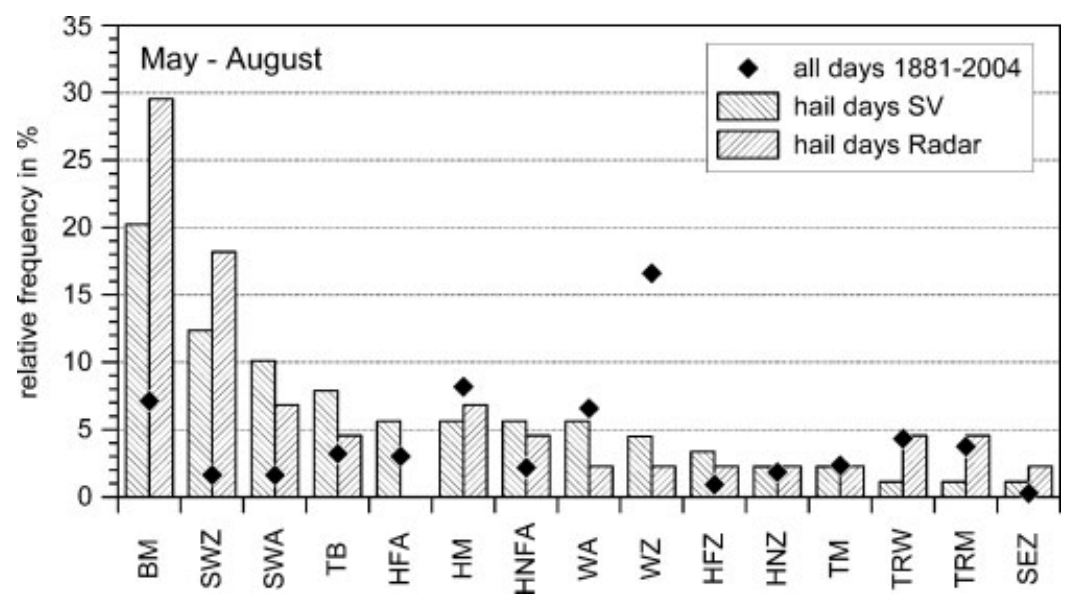

Figure 5. Mean frequency of CPs for all days (squares; mean of 1881-2004) and on hail days according to radar observations and damage reports between May and August 1996-2003. 
(a)

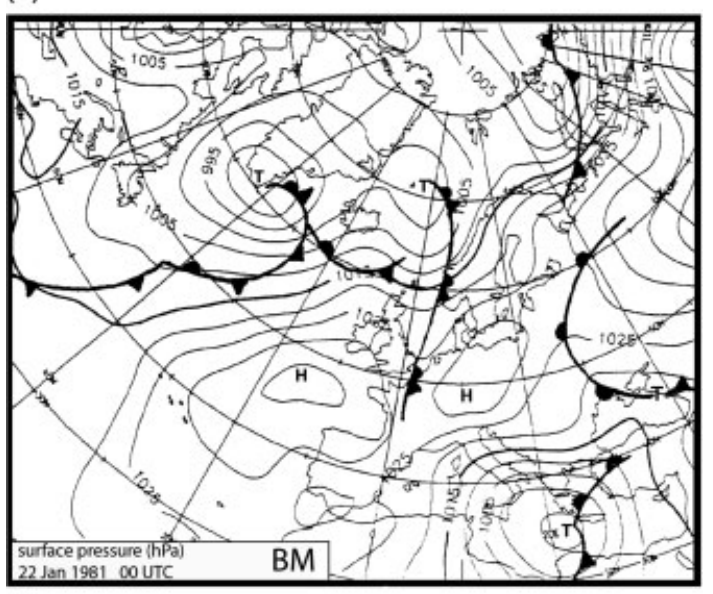

(b)

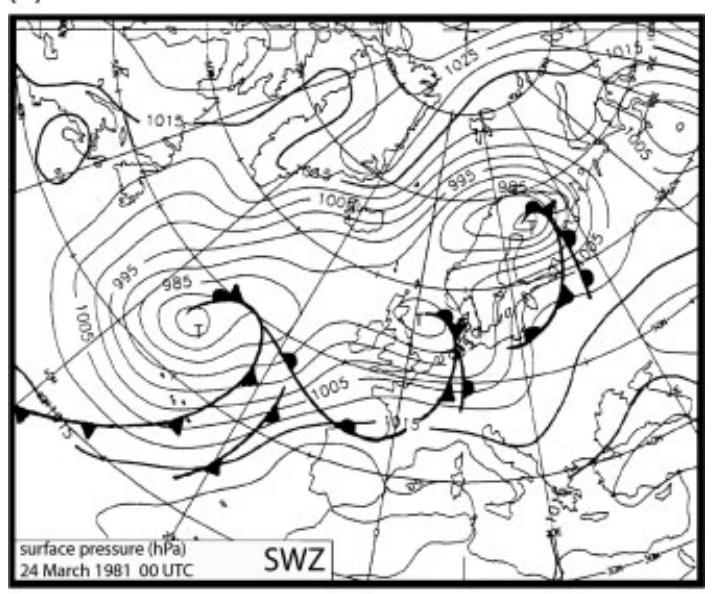

(c)

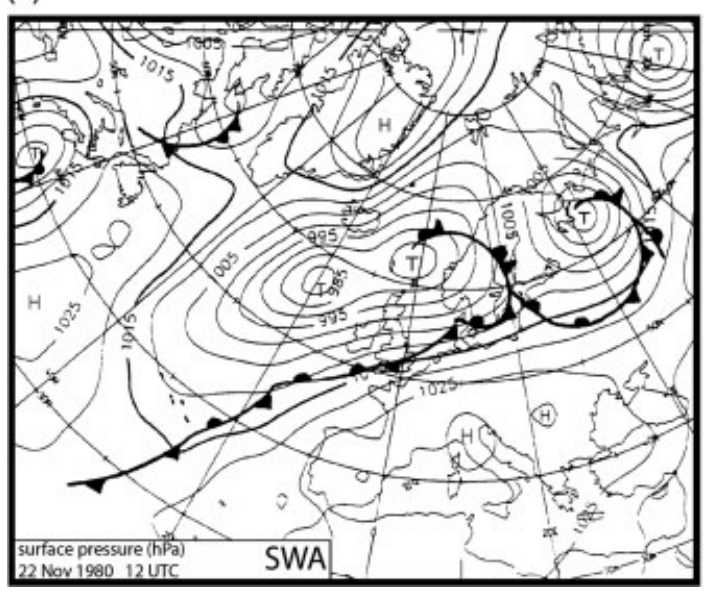

Figure 6. Examples of the three CPs that occurred most frequently on hail days: weak ridge of high pressure over Central Europe (BM), southwest cyclonic (SWZ), and southwest anticyclonic (SWA) according to Gerstengarbe and Werner (2005).

advected from the southwest. The next in line is the southwest cyclonic (SWZ) pattern. In this case, the frontal zone is located between a high-pressure system over Eastern Europe and a low-pressure system over the midNorth Atlantic. Atmospheric disturbances travel over the Bay of Biscay to Scandinavia and may trigger convection due to a sharp temperature decrease after a cold-front passage and by associated large-scale lifting. The last of the three main CPs is the southwest anticyclonic (SWA) pattern, where the frontal zone stretches between a high-pressure system over Southern Europe and Western Russia and a low-pressure system over the northern Atlantic. Convection may be triggered by large-scale lifting due to positive vorticity advection or the positive advection of layer thickness.

In total, $55 \%$ of the hail days derived from radar data, and $43 \%$ of the days determined from insurance data were restricted to the three main CPs. However, when considering all days of the summer half-year - including all thunderstorm days - the three CPs account for only $10.4 \%$ of the days, whereas the highest frequency is given for the west cyclonic (WZ) pattern, followed by highpressure Central Europe (HM). Both CPs are of minor importance to hailstorms. Twelve of the 30 different CPs with a mean frequency of $29.8 \%$ for all days are not related to hail events as identified by radar or loss data.

During the relevant period from 1974 to 2003, a positive trend for all three CPs that favour the development of hailstorms is obvious (Figure 7). Due to similar properties concerning the advection of air masses, SWA and SWZ are combined. These two southwest patterns show an annual variation between zero and 30 days a year. The positive trend indicated is significant on a $95 \%$ level. This, not only holds for the sum, but also for each of the patterns. However, the positive trend for BM is not significant because of the high annual variability between 4 and 54 days. In the period from 1986 to 1991, a kind of plateau can be seen that is not reflected by the damage data.

\subsection{Pre-convective environment}

Several convective indices derived from 12:00 UTC radio soundings at Stuttgart are used to examine longterm variations and possible trends of static stability. All indices used in this study are listed and explained in Table A1 in the Appendix. A detailed discussion of various indices and their relation to thunderstorm

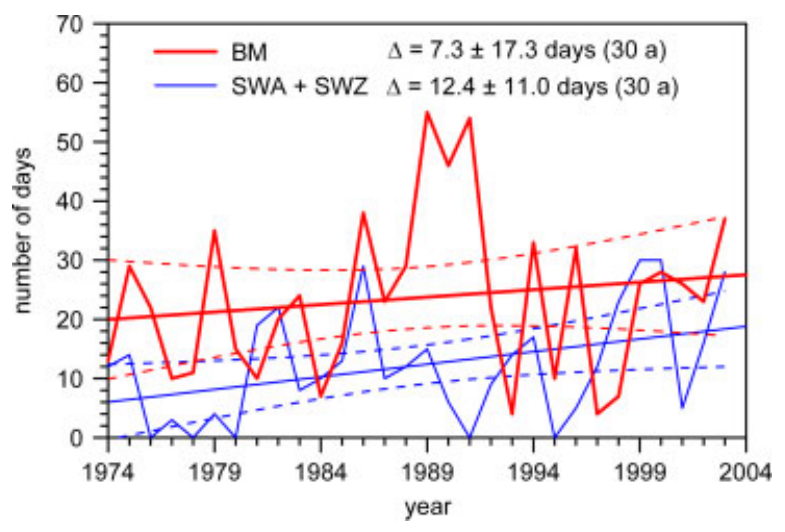

Figure 7. Number of days within the summer half-year (April-Sept.) with three different CPs that favour hailstorms: ridge central Europe (BM, red/bold) and the sum of southwest anticyclonic and cyclonic (SWA + SWZ, blue/thin) patterns. Indicated trend and confidence intervals as in Figure 4. This figure is available in colour online at www.interscience.wiley.com/ijoc 
occurrences can be found in the study of Kunz (2007a) for the same region.

The differences of atmospheric characteristics on nonthunderstorm days and on hail days are illustrated by the $\mathrm{CAPE}_{\mathrm{CCL}-\mathrm{S}}$ as integrated from the convective condensation level (CCL) to the equilibrium level (EL) and assuming a surface-based parcel (S) that was lifted. CAPE represents the positive buoyancy of an air parcel initially lifted from the boundary layer upwards through the atmosphere. Hail days, as identified by radar or SV damage data, generally exhibit higher CAPE values, indicating a higher thunderstorm potential (Figure 8). For half the hail days as detected by the radar, the CAPE was lower than $1000 \mathrm{~J} \mathrm{~kg}^{-1}$, for $32 \%$ it was between 1000 and $2500 \mathrm{~J} \mathrm{~kg}^{-1}$, and for $18 \%$ it was in excess of $2500 \mathrm{~J} \mathrm{~kg}^{-1}$. The frequency distributions on hail days, whether detected by radar data or loss data, are almost the same. In contrast to this, a clear separation can be seen for the non-thunderstorm days as determined from SYNOP stations. On days without thunderstorm observations, CAPE values are lower in general, yielding a maximum of days below a CAPE of $100 \mathrm{~J} \mathrm{~kg}^{-1}$. The few cases with a higher CAPE, but without thunderstorm observation, may be attributed to an air mass change, a stable boundary layer, as well as a lack of SYNOP observations.

The analyses reveal that the prevailing atmospheric conditions are a basic prerequisite for the development of severe thunderstorms in general, even if synoptic-scale or local-scale lifting mechanisms are decisive for the definite triggering of convection.

\subsection{Long-term change of convective indices}

The rising number of hail days and claims in the past decades as shown in Section 3 may be attributed to two different scenarios concerning atmospheric stability: the number of days with a potential for deep convection could have increased and/or atmospheric instability on thunderstorm days could have increased. To examine

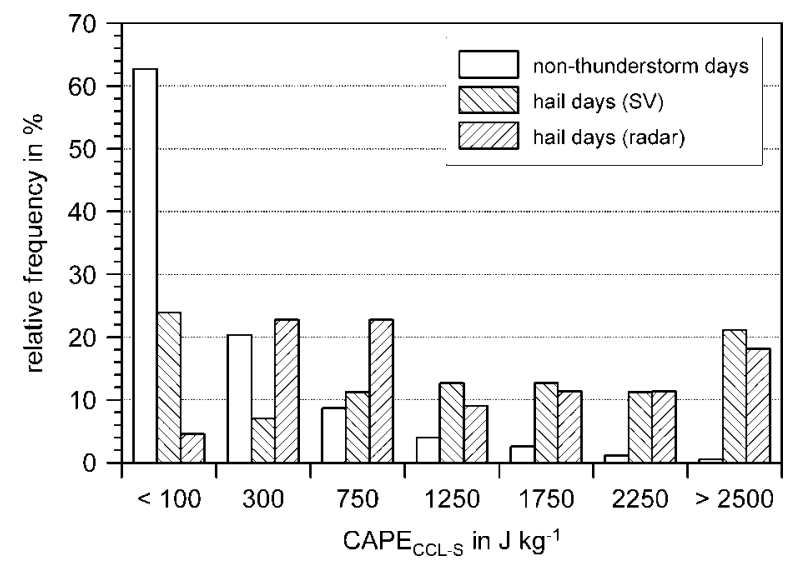

Figure 8. Histogram of $\mathrm{CAPE}_{\mathrm{CCL}-\mathrm{S}}$ (integrated from the CCL to the EL for a parcel that was lifted from the surface) for non-thunderstorm days according to reports at the SYNOP stations, and hail days according to building damage reports (SV) and radar data between 1996 and 2003 (April-Sept.). the two possible scenarios separately, the analyses to follow are based on both the number of days per year above a certain threshold and different percentiles of the respective convective index. The latter are determined from the annual frequency distribution of the index for the whole 30-year period of 1974-2003.

All days within a year that exceed or fall below two different thresholds are determined for several convective indices. The applied thresholds listed in Table A2 in the Appendix were found to be most useful for the separation between thunderstorm and non-thunderstorm days (thres 1) and between hail and non-hail days (thres 2) in the previous study of Kunz (2007a) for the same region. As an example, Figure 9 shows the time series of $\mathrm{CAPE}_{\mathrm{CCL}-\mathrm{S}}$. The number of days with a CAPE $\mathrm{CCL}-\mathrm{S}_{\mathrm{S}}$ in excess of $380 \mathrm{~J} \mathrm{~kg}^{-1}$ (thres1) or $1763 \mathrm{~J} \mathrm{~kg}^{-1}$ (thres2) has increased considerably for the 30 -year period. Although the annual variability is high, both time series exhibit a positive linear trend with an increase of 19.4 (thres 1 ) and 7.5 days (thres 2 ), respectively, in 30 years on a significance level of $>95 \%$ ( $>99 \%$ according to the MK).

Opponent to the CAPE is the convective inhibition (CIN). It represents the amount of energy that is required by a lifting mechanism or surface heating to overcome stability in order to initiate thunderstorm activity. Additionally, a CIN in excess of $-150 \mathrm{~J} \mathrm{~kg}^{-1}$ is not assumed to change the result for thres 1 significantly (Figure 9(a)).
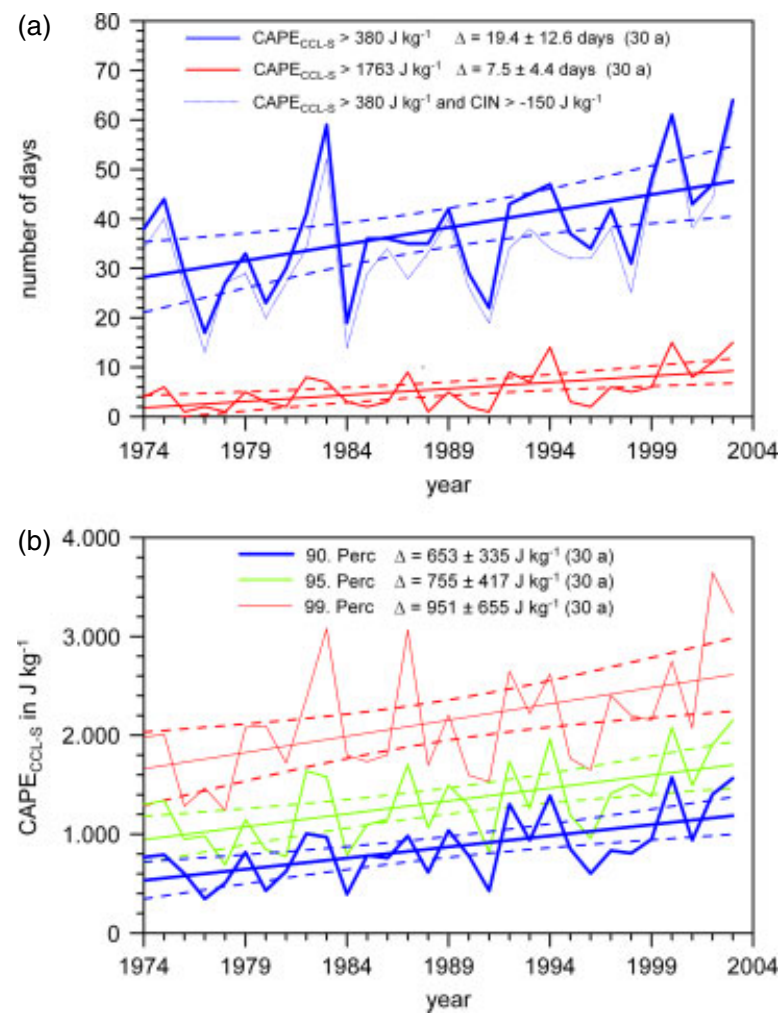

Figure 9. Number of days per year (April-Sept.) with a CAPE $\mathrm{CCL}_{\mathrm{S}}$ above two specific thresholds (solid lines) and for a combination of $\mathrm{CAPE}_{\mathrm{CCL}-\mathrm{S}}$ and CIN (thin dotted line) (a), and time series of the 90th, 95th, and 99th percentiles of the frequency distribution of $\mathrm{CAPE}_{\mathrm{CCL}-\mathrm{S}}$ (b). Indicated trend and confidence intervals as in Figure 4. This figure is available in colour online at www.interscience.wiley.com/ijoc 
The number of days per year exceeding these two thresholds generally decreases slightly, whereas the overall trend remains almost the same.

Relative linear trends, such as the ratio between the total increase during the whole period and the mean for the days above/below the two thresholds, are summarized in Figure 10. In addition to $\mathrm{CAPE}_{\mathrm{CCL}}$, we examined $\mathrm{CAPE}_{\mathrm{LFC}}$ and $\mathrm{CAPE}_{\mathrm{mul}}$ integrated from the level of free convection (LFC) or from the most unstable layer (MUL); (see Table A1 in the Appendix). Indices with a trend on a significance level below $90 \%$ are omitted. For most of the indices, the MK gives higher significance levels, indicating a possible non-linear trend. Due to reasons of consistency, a linear trend was specified exclusively for all indices. The indices can be grouped into three different categories: (1) significant positive trend $(\mathrm{Si}>90 \%)$ with an increase of up to $300 \%$ in the number of days below or in excess of a specific threshold $\left(\mathrm{KO}, \mathrm{CAPE}_{\mathrm{CCL}-\mathrm{S}}\right.$,

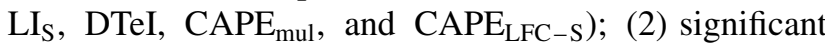
negative trend with a decrease of up to $100 \%$ (Jeff, $\mathrm{K}$, TT, SHOW, CAPE $\mathrm{LFC}-100$, and $\left.\mathrm{CAPE}_{\mathrm{LFC}-50}\right)$; and (3) no significant trend (VT, SWEAT, $\mathrm{LI}_{100}, \mathrm{~K}_{\text {mod }}$, DCI, PII, CAPE $\mathrm{CCL}_{-50}$, and $\left.\mathrm{CAPE}_{\mathrm{CCL}-100}\right)$. Comparing the two different thresholds, the linear trend as given for thres 2 exhibits higher values for both the slope and significance levels compared to those given for thresl.

For the interpretation of the results and in particular of the trend sign, we compared the number of days for thres 2 - that distinguishes best between hail days

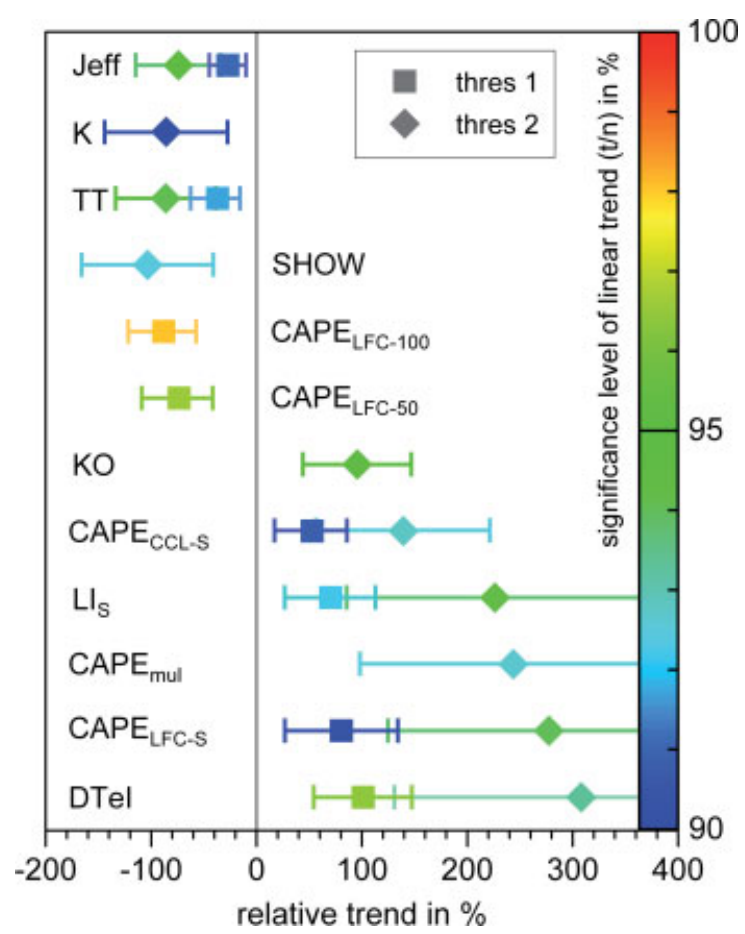

Figure 10. Relative linear trend with $95 \%$ confidence intervals of the number of days per year (April-Sept.) that are above/below two different thresholds (see Table III in the Appendix) of the convective indices within the 30-year period 1974-2003. The significance level as obtained from the $t / n$-test is indicated by the colours. This figure is available in colour online at www.interscience.wiley.com/ijoc and non-hail days - with the number of hail days per year according to the SV loss data (see Figure 4(b)). A relationship is obtained, for example, between the number of days above a specific value of $\mathrm{CAPE}_{\mathrm{CCL}-\mathrm{S}}$ (Figure 9) and the number of hail days. Although the total number of days as well as the linear trends differ between both datasets, the distinct maxima and minima more or less coincide, resulting in a high product-moment correlation coefficient of $r=0.80$ ( $r=0.74$ for the rank correlation coefficient according to Spearman). Regarding all other convective indices used in this study, an interesting result is obtained (Table A2 in the Appendix): all indices with a positive trend exhibit a correlation coefficient over 0.74 , except for KO. This means that more than $55 \%$ (coefficient of determination $B=\mathrm{r}^{2}>0.55$ ) of the annual variance of the damage-related hail days can be explained by the convective indices and, hence, by an increase of days with an unstable atmosphere. Consequently, all indices with a negative or without any trend exhibit very low correlation coefficients. Due to the comparatively small sample size, the relationship between convective indices and the number of hail days must not be considered a proof of an increase of hail frequency; it should rather be regarded as another indication of it.

To investigate possible long-term changes of atmospheric stability on thunderstorm days, we examined the variability of different percentiles of the annual statistical distribution of the convective indices: the 90th, 95th, and 99th percentiles that were approximately determined by the 165th, 174th, and 181st values of the ordered list of all 183 days in a year. Doing so, it is assumed that thunderstorms occur on days with the atmosphere exhibiting a high convective potential. As shown by Kunz (2007a), this is an appropriate assumption for most of the days. Considering again the $\mathrm{CAPE}_{\mathrm{CCL}-\mathrm{S}}$ (Figure 9(b)), characteristics similar to those of the days over specified thresholds (Figure 9(a)) can be detected. The CAPE $\mathrm{CCL}-\mathrm{S}$ exhibits a linear positive trend for all percentiles displayed. For all other indices, the percentiles and the linear trend with specified confidence intervals are listed in Table I. Again, the trend sign is the same as obtained for the number of days over certain thresholds (Figure 10). However, higher significance levels are found for the indices with a positive trend in general (note that a negative trend for $\mathrm{LI}, \mathrm{KO}$, and SHOW indicates an increase of atmospheric instability).

In order to understand the different trends of the indices and to obtain a consistent conception of the longterm variation of atmospheric stability, it is necessary to distinguish between the various methods of calculation of the convective indices. While all indices are based on both dew-point and temperature differences either between two layers or between a lifted air parcel and the environment, the basic levels considered are different. The six indices that exhibit a positive trend include temperature and/or humidity near the surface (CAPE, $\mathrm{LI}_{\mathrm{S}}$, and DTeI) or on a rather low level $(950 \mathrm{hPa}$ for $\mathrm{KO}$ ). In contrast to this, the indices with a negative 
Table I. Mean values of the 90th, 95th, and 99th percentiles of the annual frequency distribution and linear trends with confidence intervals (significance level $\mathrm{Si}=95 \%$ ) for several convective indices between 1974 and 2003 (April-Sept.). Trend values with a significance level of less than $80 \%$ according to the trend-to-noise ratio were omitted (bold numbers: significance level $>95 \%$ ).

\begin{tabular}{|c|c|c|c|c|c|c|}
\hline Index & 90th perc & 95 th perc & 99th perc & trend $_{90}$ & trend $_{95}$ & trend $_{99}$ \\
\hline \multicolumn{7}{|l|}{ (a) positive trend } \\
\hline $\mathrm{KO}($ in $\mathrm{K})$ & -7.0 & -8.9 & -12.1 & $-3.5 \pm 1.9$ & $-3.9 \pm 1.9$ & $-3.0 \pm 2.7$ \\
\hline DTeI (in K) & 1.7 & 4.4 & 8.3 & $6.8 \pm 3.4$ & $7.8 \pm 3.6$ & $8.1 \pm 3.7$ \\
\hline $\mathrm{LI}_{\mathrm{S}}($ in $\mathrm{K}$ ) & -2.1 & -3.2 & -5.1 & $-2.5 \pm 1.3$ & $-2.7 \pm 1.5$ & $-2.5 \pm 1.8$ \\
\hline $\mathrm{CAPE}_{\mathrm{mul}}\left(\right.$ in $\mathrm{J} \mathrm{kg}^{-1}$ ) & 545 & 886 & 1567 & $712 \pm 413$ & $970 \pm 563$ & $1210 \pm 731$ \\
\hline $\mathrm{CAPE}_{\mathrm{LFC}-\mathrm{S}}\left(\right.$ in $\left.\mathrm{J} \mathrm{kg}^{-1}\right)$ & 519 & 840 & 1504 & $833 \pm 435$ & $1121 \pm 585$ & $1376 \pm 769$ \\
\hline $\mathrm{CAPE}_{\mathrm{CCL}-\mathrm{S}}\left(\right.$ in $\left.\mathrm{J} \mathrm{kg}^{-1}\right)$ & 861 & 1323 & 2138 & $676 \pm 345$ & $781 \pm 433$ & $984 \pm 678$ \\
\hline \multicolumn{7}{|l|}{ (b) negative trend } \\
\hline TT (in K) & 51.2 & 52.8 & 55.7 & $-1.6 \pm 1-9$ & $-2.2 \pm 1.2$ & $-3.0 \pm 2.3$ \\
\hline $\mathrm{K}($ in $\mathrm{K})$ & 30.6 & 32.1 & 34.4 & $-1.8 \pm 1.4$ & $-2.2 \pm 1.3$ & $-2.5 \pm 1.9$ \\
\hline $\mathrm{K}_{\text {mod }}($ in $\mathrm{K}$ ) & 38.1 & 39.7 & 42.0 & $-1.6 \pm 1.3$ & $-2.0 \pm 1.3$ & $-2.9 \pm 1.9$ \\
\hline Jeff (in K) & 30.8 & 31.7 & 33.2 & $-1.6 \pm 0.7$ & $-1.6 \pm 0.6$ & $-1.7 \pm 0.8$ \\
\hline SWEAT & 190 & 219 & 269 & $-30.3 \pm 23.5$ & $-34.9 \pm 25$ & $-38.3 \pm 29.2$ \\
\hline SHOW & 0.7 & -0.2 & -1.9 & $-0.85 \pm 0.59$ & $-1.20 \pm 0.66$ & $-1.32 \pm 1.03$ \\
\hline $\mathrm{CAPE}_{\mathrm{LFC}-50}\left(\right.$ in $\left.\mathrm{J} \mathrm{kg}^{-1}\right)$ & 176 & 388 & 883 & $-174 \pm 98$ & - & - \\
\hline $\mathrm{CAPE}_{\mathrm{LFC}-100}\left(\right.$ in $\left.\mathrm{J} \mathrm{kg}^{-1}\right)$ & 114 & 269 & 719 & $-136 \pm 61$ & $-185 \pm 164$ & - \\
\hline $\mathrm{LI}_{100}($ in $\mathrm{K})$ & -0.6 & -1.5 & -3.2 & - & $0.91 \pm 0.84$ & - \\
\hline \multicolumn{7}{|c|}{ (c) no trend detectable (significance level $<80 \%$ ) } \\
\hline VT (in K) & 28.6 & 29.6 & 31.5 & - & - & - \\
\hline DCI (in K) & 20.7 & 23.5 & 28.0 & - & - & - \\
\hline PII (in $\mathrm{K} \mathrm{km}^{-1}$ ) & 1.06 & 1.58 & 2.38 & - & - & - \\
\hline $\mathrm{CAPE}_{\mathrm{CCL}-50}\left(\right.$ in $\left.\mathrm{J} \mathrm{kg}^{-1}\right)$ & 665 & 1039 & 1757 & - & - & - \\
\hline $\mathrm{CAPE}_{\mathrm{CCL}-100}\left(\mathrm{in} \mathrm{J} \mathrm{kg}^{-1}\right)$ & 583 & 908 & 1521 & - & - & - \\
\hline
\end{tabular}

trend are derived either from higher levels (lowest height $850 \mathrm{hPa}$ for TT, K, Jeff, SWEAT, and SHOW) or refer to a vertical mixing over a layer of sufficient depth (surface to $100 \mathrm{hPa}$ above for $\mathrm{LI}_{100}, \mathrm{CAPE}_{\mathrm{LFC}-100}$ ). Hence, it may be concluded that differential trends of temperature and humidity play an important role in determining the trend sign of the convective indices.

\subsection{Temperature and moisture trends}

From various studies, it is well known that the $2 \mathrm{~m}$ temperature in Baden-Württemberg increased by about $0.5-1.5 \mathrm{~K}$ in the last decades. For example, Gerstengarbe and Werner (2005) report a trend of $0.6-1.5 \mathrm{~K}$ in the mean for the period from 1951 until $2000(\mathrm{Si}>95 \%)$, KLIWA (2006) note an increase by $0.5-1.2 \mathrm{~K}$ over the period 1931-2000 ( $\mathrm{Si}>90 \%)$. If only the 12:00 UTC near-surface temperature of the sounding is considered as a mean for the summer half-year, the increase is even higher with $+2.6 \mathrm{~K}(\mathrm{Si}>95)$ for the potential temperature, $\theta$, in the period 1974-2003 (Figure 11(a)). For higher levels, the positive trend in $\theta$ weakens slightly with $+1.6 \mathrm{~K}$ at $850 \mathrm{hPa}$ and $+1.7 \mathrm{~K}$ at $700 \mathrm{hPa}$. This results in a decrease of the vertical gradient of potential temperature, as can be seen by the temporally decreasing spread between the $2 \mathrm{~m}$ and $850 \mathrm{hPa}$ trend curves. Similar characteristics are obtained for the moisture on different levels (Figure 11(b)). On the lowest level, the mixing ratio, $r$, increases by about $+1.0 \mathrm{~g} \mathrm{~kg}^{-1}$ in the 30 -year period. As obvious from the time series (red curve), the linear trend is influenced by a strong increase after the year 2000. When discarding the post-2000 years, however, there still is a positive trend of the order of $+0.4 \mathrm{~g} \mathrm{~kg}^{-1}$. For higher levels in the atmosphere, the trend is reduced or even reverses. Since the significance levels are low ( $\mathrm{Si}<90 \% / 80 \%)$, any detected trend of the mixing ratio in the middle and upper troposphere remains uncertain. The positive trend of both the temperature and mixing ratio at 12:00 UTC near the surface are confirmed by measurements at several SYNOP stations in the test area. As indicated in Figure 11, the time series at the station of Freiburg, for example, generally show a good agreement with the $2 \mathrm{~m}$ radio-sounding measurements. On the average, over all stations with $\mathrm{Si}>90 \%$, temperature increased by $1.80 \pm 0.45 \mathrm{~K}$, and mixing ratio by $1.51 \pm 0.36 \mathrm{~g} \mathrm{~kg}^{-1}$.

Due to the exponential behaviour of saturation water vapour pressure and, thus, mixing ratio as described by the Clausius-Clapeyron equation, the relative humidity near the surface shows no trend at all within the time period considered (Figure 11(b)). This holds true for the $2 \mathrm{~m}$ radio-sounding data as well as for the station data. At higher levels, however, the relative humidity exhibits a significant negative trend, particularly due to the decreasing mixing ratio (not shown).

The increase of near-surface temperature leads to higher condensation levels (LFC and LCL), but also to a higher EL. An air parcel initially lifted from the surface with increased temperature experiences stronger positive buoyancy that is proportional to $\Delta T=T-T_{U}$, where $T_{U}$ is the environment temperature. On the other side, 
(a)
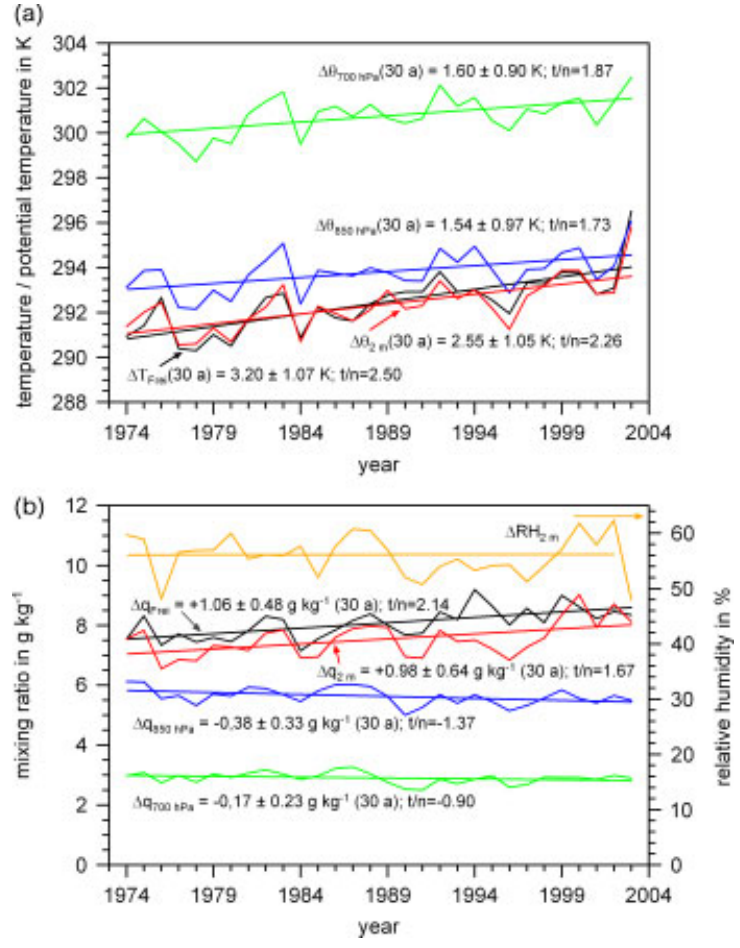

Figure 11. Time series of potential temperature (a) and mixing ratio and relative humidity (b) near the surface, at 850 and $700 \mathrm{hPa}$ from the Stuttgart sounding and the SYNOP station of Freiburg as half-year averages at 1200 UTC (April-Sept.). Indicated in both diagrams are linear trend curves and the $(\mathrm{t} / \mathrm{n})$. This figure is available in colour online at www.interscience.wiley.com/ijoc

higher moisture content of the parcel leads to a lowering of the condensation level. The release of latent heat by condensation again increases $T$ and, thus, the positive buoyancy. Concisely expressed, the positive trends of both temperature and mixing ratio at low levels lead to an increase in wet-bulb potential temperature, $\theta_{w}$, which is proportional to both parameters. Hence, warmer air parcels might be present throughout the depth of the troposphere during convection. This indicates a higher potential for deep convection and, thus, for the occurrence of severe thunderstorms.

Convective indices that consider near-surface temperature and moisture must reproduce the resulting enhancement of the potential for deep convection. Use of atmospheric values aloft only, where either no trend or no vertical differences of a trend are observable, therefore results in a negative or no significant trend in the index values. The decision as to which levels are the decisive ones for the development of deep convection is beyond the scope of the present paper. Additional studies are necessary to confirm or reject the findings of the temperature and humidity trends in the soundings as well as the daily cycle over a mesoscale region.

\section{Discussion and conclusions}

The focus of the present study considers whether there is evidence suggesting alterations in the frequency of severe thunderstorm occurrence. Particular attention is paid to hail events in the recent decades. Due to the local-scale characteristics of thunderstorms and related extremes, no single dataset exists that uniquely comprises all thunderstorm-related phenomena for a sufficiently long term.

To obtain complementary information about days with severe thunderstorms and a high convective potential of the atmosphere, datasets from different observation systems and methods were combined. Each of the datasets exhibits valuable features, but also specific constraints. Data from SYNOP stations allowed to determine the annual frequency of thunderstorm days for a long term, but considers only events in the vicinity of the station (approx. 20-km radius) and disregards storm intensity. Loss data from a building insurance company facilitates the identification of damage-causing hailstorms with high spatial coverage, but are restricted to settled regions. Circulation and weather patterns allow for the identification of large-scale situations that favour the occurrence of hailstorms, but do not differentiate on a regional scale. Finally, convective indices derived from radio-sounding observations allow to assess of atmospheric static stability and, hence, the convective potential. However, they do not consider forced ascent by large-scale lifting or local-scale convergence zones evolving over mountains.

The study presented here focused on the region of Baden-Württemberg and on the climatological period from 1974 until 2003, for which most datasets are available. The following results were obtained:

-The frequency of thunderstorm days determined from the thunderstorm reports at all SYNOP stations exhibits no trend in the mean.

-Both the amount of loss due to hail damage to buildings and the number of hail days significantly increased in the past 20 years.

-Several hail days can be attributed to southwesterly weather types. Hail-related CPs show a significant increase in the last three decades, while the highpressure pattern, BM, that occurred most frequently on hail days does not reveal any significant trend.

-All convective indices determined from temperature and moisture of the lowest layers show an increase in both extreme values and the number of days above/below certain thresholds. Convective indices based on levels above the surface exhibit either a negative or no significant trend.

-The different trend directions of the convective indices may be attributed to a strong increase of temperature and moisture in the lowest layers, and only marginal or even reverse trends aloft.

-Due to the positive trend of both, water vapour and temperature, the surface relative humidity remains approximately constant over the time interval.

In contrast to thunderstorm days as derived from SYNOP data, the number of hail days determined from insurance loss data (SV) largely increased in their frequency of occurrence. A consistent result is reported by 
Schiesser (2003) for hail damage over Switzerland. Apart from a possible change of the number or intensity of hailstorms, this increase may partly be attributed to a change of building values or an increasing use of sensitive construction material and cladding like plastics or wood (Stucki and Egli, 2007). These two points, however, can be more or less excluded as the main reasons for the positive trend, since loss data were adjusted for a variation of the portfolio and the underlying insured values. Moreover, the average claim remained almost unchanged during the 19 years considered (approx. $€ 3000$ million). It should be noted that the positive trend in the insurance loss data appears for hail damage only. Damage due to local flooding or gusts as determined from SV data in combination with meteorological observations exhibit no trend at all. Since almost all thunderstorms are associated with heavy precipitation that may cause local flooding, the different trends could be an indication of an unchanged frequency of occurrence of thunderstorms, but an increase of severe thunderstorms accompanied by hail.

If thunderstorm activity and related severe convective events actually increased in the last decades, this should be reflected by an observable change of atmospheric properties. By relating hail days to large-scale CPs, southwesterly flow patterns were found to favour the occurrence of hailstorms. The results are consistent with earlier studies, e.g. that of Schiesser (2003), who found almost the same weather patterns on hail days over Switzerland, or that of Bissolli et al. (2007), who attributed tornado events to three specific weather types. A preference of southwest weather patterns is to be expected, since warm and moist air masses are frequently advected from southwesterly directions into the test region. The increasing frequency of these specific weather patterns might also increase the potential for thunderstorms.

Apart from the circulation patterns acting on the synoptic scale, also atmospheric static stability on the regional scale may change the convective potential. We found that most of the convective indices determined from temperature and moisture in the lowest layers exhibit a positive trend significant on the $95 \%$ level as regards both extreme values in terms of different percentiles (90th, 95th, and 99th) and the number of days that exceed or fall below two specific thresholds. A relation of the latter to the annual number of hail damage days yields correlation coefficients between 0.65 (for KO Index) and 0.80 (for $\mathrm{CAPE}_{\mathrm{CCL}-\mathrm{S}}$ ). This finding confirms the relation between convective indices and the occurrence of thunderstorms already shown in a previous study (Kunz, 2007a). Furthermore, it reveals the importance of low-level properties for the development of deep convection. The negative or insignificant trends of indices computed from atmospheric properties at higher levels can be assigned to the marginal or even reverse trend in temperature and moisture aloft. The reasons for the opposing trends observed on lowest and higher levels, in particular that of moisture, are not yet fully understood. One plausible physical argument is that air masses of the free atmosphere likely have their source over the
Atlantic, where global warming exhibits a certain time delay due to the damping effect of the ocean. On the other hand, air parcels within the planetary boundary layer are altered by exchange processes between the land surface, which is strongly modified by global warming, and the atmosphere. This hypothesis is supported by the fact that the surface-based relative humidity shows no trend at all. The increase in the lower-tropospheric water vapour as well as the nearly fixed relative humidity are also projected by global climate models (Held and Soden, 2006).

In addition to the thermal stratification of the atmosphere, the vertical wind shear is another prerequisite for the development of deep convection. Organized convection like multi-cell or super-cell thunderstorms requires a strong speed and/or directional wind shear to emerge. In the Stuttgart soundings, however, vertical wind profiles too often failed to derive reliable time series to detect possible trends (e.g. 1995 and 1999 more than one month with data loss).

A limiting factor in sounding-based convective indices is the assumption that the atmospheric conditions are homogeneous before and after the sounding. When air masses with different properties are advected, for example, in conjunction with a frontal passage, the sounding cannot be representative of the whole area and the whole period. Moreover, the Stuttgart sounding at an elevation of $314 \mathrm{~m}$ asl may underestimate the convective potential over lower terrain, as it was shown by Hannesen et al. (1998) for a tornado event in the Rhine valley. Another limitation of the indices is that they represent the convective potential in the atmosphere only and do not consider forced ascent by large-scale lifting or local-scale convergence zones evolving over mountains (Barthlott et al., 2006).

To overcome these constraints, the convective indices could be combined with appropriate data from a numerical model. In a recent study, van Zomeren and van Delden (2007) combined different versions of the LI with the vertically integrated moisture flux derived from weather analysis data from the European Centre for Mediumrange Weather Forecasts (ECMWF). They showed that the prediction of severe thunderstorm days and tornado events over Europe improves significantly when employing the moisture flux in the prediction scheme.

In the future, the investigations will be extended by examining in detail the prevailing atmospheric conditions in terms of frontal passages, horizontal temperature gradients, synoptic-scale lifting ( $\omega$ - field), and objective weather-type classification that also accounts for advection, vorticity, and humidity on different levels. If a relationship to hail days can be established, this approach will be transferred and applied to regional climate simulations in order to quantify possible changes of the hailstorm potential in the future. Finally, we intend to extend the investigation area to cover the whole area of Germany as preliminary results showed an increase of convective energy in terms of the CAPE at most of the radio-sounding stations in Germany. 


\section{Acknowledgements}

The work was partly funded by the federal State of Baden-Württemberg (Ministry for the Environment and Transport) and the Landesanstalt für Umwelt, Messungen und Naturschutz Baden-Württemberg (LUBW) within the framework of the KLARA project. The authors thank the Sparkassenversicherung (SV) for the provision of detailed loss data, the German weather service for the provision of synoptic station and radiosonde data, and Oliver Weber and Heike Steller for editing the SV datasets. We thank
Dr. Nikolai Dotzek and the reviewer, Dr. Rick Grimaldi, for their constructive comments and suggestions that improved the quality of this paper.

\section{Appendix A}

6.1. Definition of convective indices

The definition of the convective indices used in this study can be found in Table A1. Table A2 lists two different thresholds that are used for the investigation of days

A1. Summary of convective parameters and indices: $T, T d$, and $T_{v}$ are temperature, dew-point temperature, and virtual temperature (in ${ }^{\circ} \mathrm{C}$ ), $\theta, \theta_{e}$, and $\theta_{w}$ are potential temperature, equivalent potential temperature, and wet-bulb potential temperature(inK), $Z$ is the geopotential height (in gpm), and $R_{d}$ is the gas constant for dry air $\left(=287.1 \mathrm{~J} \mathrm{~K}^{-1} \mathrm{~kg}^{-1}\right.$ ). The subscripts are referred to as constant pressure level ( $\mathrm{s}$ is the surface) and an arrow indicates the vertical lifting of an air parcel.

\begin{tabular}{|c|c|c|}
\hline Index/Equation & Comment & Reference \\
\hline $\begin{array}{l}\text { Vertical Totals } \\
\mathrm{VT}=T_{850}-T_{500}\end{array}$ & & Miller (1972) \\
\hline $\begin{array}{l}\text { Lifted Index } \\
\mathrm{LI}_{\mathrm{X}}=T_{500}-T^{\prime}{ }_{\mathrm{i} \rightarrow 500}\end{array}$ & $\begin{array}{l}\mathrm{X} \text { : parcels } p, T, \text { and } T d \text { near-surface }\left(\mathrm{LI}_{\mathrm{S}}\right) \\
\text { or averaged over the lowest } 100 \mathrm{hPa}\left(\mathrm{LI}_{100}\right)\end{array}$ & Galway (1956) \\
\hline $\begin{array}{l}\text { Showalter Index } \\
\text { SHOW }=T_{500}-T^{\prime}{ }_{850 \rightarrow 500}\end{array}$ & & Showalter (1953) \\
\hline Deep Convective Index & & Barlow (1993) \\
\hline \multicolumn{3}{|l|}{$\mathrm{DCI}=(T+T d)_{850}-\mathrm{LI}_{100}$} \\
\hline $\begin{array}{l}\text { Convective available potential energy } \\
\mathrm{CAPE}_{\mathrm{LFC} / \mathrm{CCL}-\mathrm{X}}=R_{\mathrm{d}} \int^{\mathrm{EL}}\left(T_{\mathrm{v}}^{\prime}-T_{\mathrm{v}}\right) \mathrm{d} \ln p\end{array}$ & $\begin{array}{l}T_{\mathrm{v}}{ }^{\prime} \text { is the virtual temperature of an air } \\
\text { parcel lifted from a certain layer (X: } p, T \text {, } \\
\text { and } T d \text { averaged over the lowest } \mathrm{X} \mathrm{hPa} \text { or } \\
\text { from the surface) to the equilibrium level. } \\
\text { The integration starts either from the level } \\
\text { of free convection or the convective } \\
\text { condensation level. }\end{array}$ & Moncrieff and Miller (1976) \\
\hline $\mathrm{CAPE}_{\mathrm{mul}}$ & $\begin{array}{l}\text { CAPE calculated for a parcel with } T, T d \text {, } \\
\text { and } p \text { on the level of maximum } \theta_{\mathrm{e}} \text { at the } \\
\text { lowest } 250 \mathrm{hPa}\end{array}$ & \\
\hline $\begin{array}{l}\text { KO Index } \\
\mathrm{KO}=0.5\left[\left(\theta_{\mathrm{e} 500}+\theta_{\mathrm{e} 500}\right)-\left(\theta_{\mathrm{e} 850}+\theta_{\mathrm{e} 950}\right)\right]\end{array}$ & In this study, we used $\theta_{\mathrm{e} 950}$ instead of $\theta_{\mathrm{e} 1000}$ & Andersson et al. (1989) \\
\hline $\begin{array}{l}\text { Delta Theta-E } \\
\text { DTeI }=\theta_{\mathrm{eS}}-\theta_{\mathrm{e} 300}\end{array}$ & & Atkins and Wakimoto (1991) \\
\hline $\begin{array}{l}\text { Potential Instability Index } \\
\mathrm{PII}=\left(\theta_{\mathrm{e} 925}-\theta_{\mathrm{e} 500}\right) /\left(Z_{500}-Z_{925}\right)\end{array}$ & & van Delden (2001) \\
\hline $\begin{array}{l}\text { Total Totals Index } \\
\mathrm{TT}=(T+T d)_{850}-2 T_{500}\end{array}$ & & Miller (1972) \\
\hline $\begin{array}{l}\text { K-Index } \\
K=\left(T_{850}-T_{500}\right)+T d_{850}-(T-T d)_{700}\end{array}$ & & George (1960) \\
\hline $\begin{array}{l}\text { Modified K-Index } \\
\mathrm{K}_{\mathrm{mod}}=\left(T^{*}-T_{500}\right)+T d^{*}-(T-T d)_{700}\end{array}$ & $\begin{array}{l}T^{*} \text { and } T d^{*} \text { are averaged between the } \\
\text { surface and } 850 \mathrm{hPa}\end{array}$ & Charba (1977) \\
\hline $\begin{array}{l}\text { Jefferson Index } \\
\text { Jeff }=1.6 \theta_{\mathrm{w} 850}-T_{500}-0.5\left(\mathrm{~T}_{700}-\mathrm{Td}_{500}\right)-8\end{array}$ & & Jefferson (1963) \\
\hline $\begin{array}{l}\text { Severe weather threat index } \\
\text { SWEAT }=\text { fct }(T d, T T, f, d)\end{array}$ & $\begin{array}{l}\text { Also considers wind speed } f \text { and direction } \\
d \text { at different levels }\end{array}$ & Miller (1972) \\
\hline
\end{tabular}


A2. Thresholds of the convective indices used in the study to investigate the temporal variability of days with a high convective potential, thres 1 and thres2, and correlation coefficient, $r$, between the annual number of hail days ( $>10$ claims; see Figure 3) and days above/below thres2 (thres1: separation between thunderstorm days and non-thunderstorm days; thres 2 : separation between hail days and non-hail days according to Kunz, 2007a).

\begin{tabular}{|c|c|c|c|}
\hline Index & thres1 & thres2 & $r$ \\
\hline \multicolumn{4}{|c|}{ (a) positive trend } \\
\hline $\mathrm{KO}$ & $\leq-0.31 \mathrm{~K}$ & $\leq-6.32 \mathrm{~K}$ & 0.65 \\
\hline DTeI & $\geq-1.94 \mathrm{~K}$ & $\geq 10.3 \mathrm{~K}$ & 0.75 \\
\hline $\mathrm{LI}_{\mathrm{S}}$ & $\leq-0.22 \mathrm{~K}$ & $\overline{\leq}-4.19 \mathrm{~K}$ & 0.76 \\
\hline $\mathrm{CAPE}_{\mathrm{mul}}$ & $\geq 159 \mathrm{~J} \mathrm{~kg}^{-1}$ & $\geq 1474 \mathrm{~J} \mathrm{~kg}^{-1}$ & 0.74 \\
\hline $\mathrm{CAPE}_{\mathrm{LFC}-\mathrm{S}}$ & $\geq 170 \mathrm{~J} \mathrm{~kg}^{-1}$ & $\geq 1474 \mathrm{~J} \mathrm{~kg}^{-1}$ & 0.75 \\
\hline $\mathrm{CAPE}_{\mathrm{CCL}-\mathrm{S}}$ & $\geq 380 \mathrm{~J} \mathrm{~kg}^{-1}$ & $\geq 1763 \mathrm{~J} \mathrm{~kg}^{-1}$ & 0.80 \\
\hline \multicolumn{4}{|c|}{ (b) negative trend } \\
\hline TT & $\geq 48.1 \mathrm{~K}$ & $\geq 52.2 \mathrm{~K}$ & -0.63 \\
\hline $\mathrm{K}$ & $\geq 26.1 \mathrm{~K}$ & $\geq 31.9 \mathrm{~K}$ & -0.22 \\
\hline $\mathrm{K}_{\text {mod }}$ & $\geq 33.9 \mathrm{~K}$ & $\geq 38.9 \mathrm{~K}$ & -0.09 \\
\hline Jeff & $\geq 27.9 \mathrm{~K}$ & $\geq 30.6 \mathrm{~K}$ & -0.40 \\
\hline SWEAT & $\geq 134$ & $\geq 221$ & -0.22 \\
\hline SHOW & $\leq 2.51$ & $\leq-0.85$ & 0.05 \\
\hline $\mathrm{LI}_{100}$ & $\leq 1.76 \mathrm{~K}$ & $\leq-2.07 \mathrm{~K}$ & 0.10 \\
\hline $\mathrm{CAPE}_{\mathrm{LFC}-50}$ & $\geq 48 \mathrm{~J} \mathrm{~kg}^{-1}$ & $\geq 936 \mathrm{~J} \mathrm{~kg}^{-1}$ & 0.26 \\
\hline CAPE $_{\text {LFC }-100}$ & $\geq 29 \mathrm{~J} \mathrm{~kg}^{-1}$ & $\geq 688 \mathrm{~J} \mathrm{~kg}^{-1}$ & 0.16 \\
\hline \multicolumn{4}{|c|}{ (c) no trend (significance level $<80 \%$ ) } \\
\hline VT & $\geq 26.9 \mathrm{~K}$ & $\geq 28.6 \mathrm{~K}$ & 0.46 \\
\hline DCI & $\geq 15.3 \mathrm{~K}$ & $\geq 25.7 \mathrm{~K}$ & 0.27 \\
\hline PII & $\geq-0.17 \mathrm{~K} \mathrm{~km}^{-1}$ & $\geq 1.9 \mathrm{~K} \mathrm{~km}^{-1}$ & 0.38 \\
\hline $\mathrm{CAPE}_{\mathrm{CCL}-50}$ & $\geq 220 \mathrm{~J} \mathrm{~kg}^{-1}$ & $\geq 1544 \mathrm{~J} \mathrm{~kg}^{-1}$ & 0.17 \\
\hline $\mathrm{CAPE}_{\mathrm{CCL}-100}$ & $\geq 214 \mathrm{~J} \mathrm{~kg}^{-1}$ & $\geq 1207 \mathrm{~J} \mathrm{~kg}^{-1}$ & 0.26 \\
\hline
\end{tabular}

with a potential for the development of deep convection and gives the correlation coefficient between the annual number of hail days and days above/below a specific threshold of the indices.

\section{References}

Andersson T, Andersson M, Jacobsson C, Nilsson S. 1989. Thermodynamic indices for forecasting thunderstorms in southern Sweden. Meteorological Magazine 116: 141-146.

Atkins N, Wakimoto R. 1991. Wet microburst activity over the southeastern United States: implications for forecasting. Weather and Forecasting 6: 470-482.

Barlow W. 1993. A new index for the prediction of deep convection. Preprints of the 17th Conference on Severe Local Storms, St. Louis, 4-8 October: 129-132.

Barthlott C, Corsmeier U, Meißner C, Braun FJ, Kottmeier C. 2006. The influence of mesoscale circulation systems on triggering convective cells over complex terrain. Atmospheric Research 81: $150-175$.

Bissolli P, Dittmann E. 2001. The objective weather types classification of the German Weather Service and its possibilities of application to environmental and meteorological investigations. Meteorologische Zeitschrift 10: 253-260.

Bissolli P, Grieser J, Dotzek N, Welsch M. 2007. Tornadoes in Germany 1950-2003 and their relation to particular weather conditions. Global and Planetary Change 57: 124-138.

Charba J. 1977. Operational System for Predicting Thunderstorms Two to Six Hours in Advance. Technical Report, NO AA NWS TDL64. Techniques Development Laboratory, National Weather Service: Silver Spring. van Delden A. 2001. The synoptic setting of thunderstorms in Western Europe. Atmospheric Research 56: 89-110.

Doswell CA III. 1987. The distinction between large-scale and mesoscale contributions to severe convection: A case study example. Weather and Forecasting 2: 3-16.

Dotzek N. 2001. Tornadoes in Germany. Atmospheric Research 56: $233-251$.

Dotzek N. 2003. An updated estimate of tornado occurrence in Europe. Atmospheric Research 67-68: 153-161.

Fuelberg HE, Biggar DG. 1994. The preconvective environment of summer thunderstorms over the Florida Panhandle. Weather and Forecasting 9: 316-326.

Galway J. 1956. The lifted index as a predictor of latent instability. Bulletin of the American Meteorological Society 37: 528-529.

George J. 1960. Weather Forecasting for Aeronautics. Academic Press: New York.

Gerstengarbe FW, Werner PC. 2005. Katalog der Großwetterlagen Europas (1881-2004) nach Paul Hess und Helmuth Brezowsky. Technical Report 100. Potsdam Institute for Climate Impact Research (PIK): Potsdam; 153.

Groenemeijer P, van Delden A. 2007. Sounding-derived parameters associated with large hail and tornadoes in the Netherlands. Atmospheric Research 83: 473-487.

Gysi H. 1995. Niederschlagsmessung mit Radar in orographisch gegliedertem Gelände. Ph.D. thesis. Institute for Meteorology and Climate Research, University of Karlsruhe.

Gysi H. 1998. Orographic influence on the distribution of accumulated rainfall with different wind directions. Atmospheric Research 47-48: 615-633.

Haklander AJ, van Delden A. 2003. Thunderstorm predictors and their forecast skill for the Netherlands. Atmospheric Research 67-68: 273-299.

Hannesen R, Dotzek N, Gysi H, Beheng KD. 1998. Case study of a tornado in the Upper Rhine valley. Meteorologische Zeitschrift 7: $163-170$.

Held IM, Soden BJ. 2006. Robust responses of the hydrological cycle to global warming. Journal of Climate 19: 5686-5699.

Hess P, Brezowsky H. 1977. Katalog der Großwetterlagen Europas. Technical Report 113. Berichte des Deutschen Wetterdienstes: Offenbach; 68.

Houze RA. 1993. Cloud Dynamics. Academic Press: San Diego.

Huntrieser H, Schiesser H, Schmid W, Waldvogl A. 1997. Comparison of traditional and newly developed thunderstorm indices for Switzerland. Weather and Forecasting 12: 108-125.

IPCC. 2007. Climate Change 2007: The Physical Science Basis, Contribution of Working Group I to the Fourth Assessment Report of the Intergovernmental Panel on Climate Change. Cambridge University Press: Cambridge. http://www.ipcc.ch/ipccreports/ar4wg1.htm

Jefferson G. 1963. A further development of the stability index. Meteorological Magazine 92: 313-316.

KLIWA. 2006. Our Climate Is Changing: Consequences - ExtentStrategies. Climate Change and Water Resource Management (KLIWA). http://www.kliwa.de/download/KLIWA_en. pdf: 18.

Kunz M. 2007a. The skill of convective parameters and indices to predict isolated and severe thunderstorms. Natural Hazards and Earth System Sciences 7: 327-342.

Kunz M. 2007b. Von Wettersystemen zu Extremereignissen: Gefährdungsanalyse über orografisch strukturiertem Gelände. Abschluss symposium 2007 Graduiertenkolleg Naturkatastrophen, Karlsruhe: 195-203.

Lee RR, Passner JE. 1993. The development and verification of TIPS: An expert system to forecast thunderstorm occurrence. Weather and Forecasting 8: 271-280.

Meißner C, Kalthoff N, Kunz M, Adrian G. 2007. Initiation of shallow convection in the Black Forest Mountains. Atmospheric Research 86: 42-60. DOI: 10.1016/j.atmosres.2007.03.003.

Miller R. 1972. Notes on Analysis and Severe Storm Forecasting Procedures of the Air Force Global Weather Central. Technical Report 200, AWS, U.S. Air Force: 102.

Moncrieff M, Miller M. 1976. The dynamics and simulation of tropical cumulonimbus and squall lines. Quarterly Journal of the Royal Meteorological Society 102: 373-394.

Niall S, Walsh K. 2005. The impact of climate change on hailstorms in southeastern Australia. International Journal of Climatology 25: 1933-1952. 
Rasmussen E, Blanchard D. 1998. A baseline climatology of soundingderived supercell and tornado forecast parameters. Weather and Forecasting 13: 1148-1164.

Schiesser H. 2003. Hagel. In: Extremereignisse und Klimaänderung. Organe consultatif sur les changements climatiques (OcCC): Bern; 65-68. http://www.proclim.ch/Products/Extremereignisse03/ Extrem03_Bericht.html.

Schönwiese CD. 2000. Praktische Statistik für Meteorologen und Geowissenschaftler. Gebrüder Borntraeger: Berlin.

Showalter A. 1953. A stability index for thunderstorm forecasting. Bulletin of the American Meteorological Society 34: 250-252. von Storch H, Zwiers FW. 2004. Statistical Analysis in Climate Research. Cambridge University Press: Cambridge.

Stucki M, Egli T. 2007. Synthesebericht Elementarschutzregister Hagel. Präventionsstiftung der kantonalen Gebäudeversicherungen: Bern: 35.

Yarnal B, Comrie A, Frakes B, Brown D. 2001. Review: developments and prospects in synoptic climatology. International Journal of Climatology 21: 1923-1950.

van Zomeren J, van Delden A. 2007. Vertically integrated moisture flux convergence as a predictor of thunderstorms. Atmospheric Research 83: $435-445$. 